

\section{¿ES ÉTICAMENTE JUSTIFICABLE EL PATERNALISMO JURÍDICO? *}

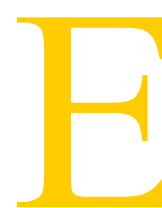

n su influyente ensayo On liberty (1859), John Stuart Mill afirmaba:

«...el único fin en aras del cual la humanidad, individual o colectivamente está autorizada a interferir con la libertad de acción de cualquiera de sus miembros es la auto protección... el único propósito para el cual el poder puede ser correctamente ejercido sobre cualquier miembro de una sociedad civilizada, en contra de su propia voluntad, es el evitar un daño a los demás. No puede correctamente ser obligado a hacer $\mathrm{u}$ omitir algo porque sea mejor para él hacerlo así, porque ello vaya a hacerlo más feliz, porque, según la opinión de los demás, hacerlo sería sabio o hasta correcto» $(1978,135)$.

La intervención coactiva en el comportamiento de una persona a fin de evitar que se dañe a sí misma es generalmente llamada "paternalismo» y desde la formulación radical de Mill, ha sido objeto de una no siempre fecunda discusión. Si Rousseau podía todavía hablar de la «autoridad paternal» como de lo más opuesto al «espíritu feroz del despotismo» (1964/III, 182), no son pocos hoy quienes sienten una marcada aversión frente a los términos «paternalismo» o «paternal» y prefieren recurrir a expresiones tales como «intervencionismo» o «principio de bienestar» para designar los apartamientos éticamente justificados del principio del daño a terceros. En la presente exposición habré de utilizar preferentemente el término «paternalismo» sin recurrir a eufemismos.

En los últimos años, la aparición del llamado «neoconservadurismo» y su consecuente esfuerzo por desmantelar el Estado social, considerado también como una forma moralmente inaceptable de «agresión paternalista» (Robert Nozick, 1974, 34),

\footnotetext{
* Una primera versión de este trabajo fue publicado en Revista Latinoamericana de Filosofía, vol XIII, núm. 3, Buenos Aires, 1987.
} 
por una parte, y la existencia en nuestras sociedades de medidas francamente paternalistas que parecen tener un elevado grado de plausibilidad (tales como la prohibición de la venta de drogas, la imposición del uso de cinturones de seguridad en los automóviles o la obligación de hacer aportes jubilatorios, las disposiciones sobre la incapacidad jurídica de los débiles mentales, pródigos, alcohólicos o drogadictos) por otra, ha reactualizado la lectura de Mill y encendido una vez más la polémica acerca de si debe o no admitirse como único principio de justificación ética de la coacción estatal la prevención o el castigo de daños infligidos a terceros o si también existen tipos de paternalismo que son justificables éticamente.

En lo que sigue, me propongo lo siguiente:

I. Establecer algunas diferencias conceptuales entre el paternalismo jurídico y otras formas de coacción estatal que presentan algunas semejanzas con aquél desde el momento en que se apartan del principio del daño a terceros propiciado por Mill.

II. Analizar los argumentos que suelen se formulados en contra del paternalismo jurídico.

III. Considerar la posibilidad de establecer tipos de paternalismo jurídico justificables éticamente.

El paternalismo jurídico sostiene que siempre hay una buena razón en favor de una prohibición o de un mandato jurídico, impuesto también en contra de la voluntad del destinatario de esta prohibición o mandato, cuando ello es necesario para evitar un daño (físico, psíquico o económico) de la persona a quien se impone esta medida. Tal es el caso de las disposiciones relacionadas con la obligación de usar casco protector en las motos, de las leyes que prohíben bañarse en playas donde no hay bañeros, de la prohibición de venta de medicamentos sin receta, de las leyes que prohíben ciertos juegos de azar aduciendo que ellos suelen atraer más a los pobres que a los ricos, con el consiguiente perjuicio para aquéllos.

El problema del paternalismo jurídico suele ser también tratado dentro de un contexto más amplio, es decir, el de una posible función moralizante del orden jurídico, que no se limitaría a procurar prevenir daños físicos, psíquicos o económicos, sino que también podría prohibir conductas por considerarlas intrínsecamente 
inmorales. Como es sabido, Lord Devlin ha sostenido esta posición que ha sido llamada «moralismo jurídico». Ejemplos al respecto pueden ser la prohibición de la homosexualidad entre adultos, de sex-shows o de actividades sexuales como la de Miss Tan, quien en un periódico londinense publicó el siguiente anuncio:

«Entusiasta de la humillación, mi pasatiempo favorito es humillar y disciplinar hombres maduros y sumisos, fuertemente atados; dama encantadoramente bronceada invita humildes solicitantes, TV y ropa de cuero, 12 del mediodía hasta 7 de la tarde.» (Cfr. Tur, 1985, 176 y sigs.)

Se consideró que los servicios prestados por Miss Tan eran de naturaleza «particularmente repugnantes y perversos» y aun cuando los clientes se sometían a ellos por su propia voluntad y pleno consentimiento, significaban un insulto a la decencia publica. Miss Tan fue condenada a seis meses de arresto domiciliario y los voluntarios candidatos a ser humillados se vieron privados de sus servicios.

Existen otras dos formas de intervención coactiva relacionadas aunque no idénticas con el paternalismo jurídico propiamente dicho: cuando el Estado interviene con el propósito de asegurar un beneficio (físico, psíquico o económico) del destinatario de la medida en cuestión; y el perfeccionismo: siempre es una buena razón en apoyo de una prohibición jurídica sostener que es probablemente necesaria para perfeccionar el carácter de la persona a quien se le impone (cfr. Feinberg, 1984, 27). En estos dos tipos de intervenciones la idea de aumentar o promover el bien es la decisiva y es considerada por algunos como la única justificación éticamente admisible (cfr. Dan Brock, 1983).

He de dejar de lado aquí los problemas vinculados con el moralismo jurídico, sin perjuicio de volver al final a plantear la cuestión de hasta qué punto es posible justificar el paternalismo jurídico sin recurrir de algún modo al moralismo jurídico y asumir una posición contraria a lo que Neil MacCormick ha llamado «el principio del moral disestablishment» (1982, 18-38).

\section{II}

Tres son los argumentos que básicamente se hacen valer en contra del paternalismo jurídico: 
1. el argumento utilitarista,

2. el argumento del respeto a la autonomía de la persona,

3. el argumento de la violación del principio de igualdad.

1. El argumento utilitarista fue ya formulado por el propio Mill y puede ser resumido de la siguiente manera:

a) Nadie es mejor juez que uno mismo con respecto a lo que daña o no daña los propios intereses: «...el hombre o la mujer más común tiene (al respecto) medios de conocimiento que superan inconmensurablemente aquéllos que puede poseer cualquier otro» (1978, 207).

b) «Las interferencias de la sociedad para anular su juicio y sus propósitos en aquello que únicamente le compete al individuo tienen que estar basadas en presunciones generales, que pueden ser todas equivocadas $\mathrm{y}$, si son correctas, es probable que sean mal aplicadas a los casos individuales» $(1978,207)$.

c) «Todos los errores que el individuo puede cometer en contra del consejo y la advertencia están contrarrestados por lejos por el mal de permitir a otros que lo obliguen a hacer aquello que consideran que es su bien» $(1978,207)$.

d) «La humanidad sale ganando si permite que cada cual viva como le parezca bien y no lo obliga a vivir como le parece bien al resto» $(1978,138)$.

Si las premisas de Mill pretenden ser universalmente válidas son, sin duda, falsas.

En efecto, no es verdad que siempre sepamos mejor que nadie cuáles son nuestros reales intereses y mucho menos sabemos con exactitud qué medidas pueden promoverlos o dañarlos. El mismo Mill vio que tal es el caso por lo menos en dos circunstancias:

a) Cuando alguien cree que lo que más le conviene es firmar un contrato de esclavitud y renunciar de esta manera a su libertad para siempre. Estos contratos deben estar absolutamente prohibidos aun cuando quien los firma lo haga voluntariamente y convencido que ello satisface sus intereses (por ejemplo, obtener una suma de dinero que le permita salvar a sus hijos de la miseria y del hambre). Pero si ello es así, con la introducción de la libertad como valor absoluto, se abandona la línea del argumento utilitarista. La salida de Mill será sostener que la libertad es una condición necesaria de la felicidad individual o colectiva. (Como contraejemplo podría pensarse en los campesinos 
libres de Castilla y León que en la Alta Edad Media renunciaban voluntariamente a su libertad en aras de la seguridad que les brindaba el señor feudal; y para los casos individuales, la felicidad que pretende tener una monja de clausura (pretensión que debería ser respetada según el argumento de que cada cual es el mejor juez de sus propios intereses.)

b) El segundo caso es aquél en el que los ciudadanos no han llegado a un nivel de desarrollo comparable con el de los pueblos civilizados de Europa:

«El despotismo es un modelo legítimo de gobierno para manejar los bárbaros, dado el fin de su promoción y los medios realmente destinados a tal fin. La libertad, como principio, no tiene aplicación a ningún estado de cosas anterior al tiempo en el cual la humanidad se ha vuelto capaz de ser mejorada por la discusión en libertad e igualdad» $(1978,136)$.

En ambos casos, el o los sujetos sometidos a la acción paternalista parecen presentar algún tipo de déficit, debilidad o incompetencia que justificaría una excepción al principio del daño a terceros como fundamento exclusivo de la coacción estatal. El argumento de las presunciones generales es por cierto paradójico, como lo ha señalado Lyons $(1984,174)$ :

«Se basa en la suposición de que sabemos lo suficiente acerca de cómo la gente ha sido afectada por acciones pasadas para concluir que sus intereses han sido afectados por los intentos pasados de intervención paternalista. Pero ello sugiere que tenemos conocimiento suficiente de los intereses de los otros y esto parece estar en conflicto con la idea de que no conocemos los intereses de los otros lo suficientemente bien como para determinar cuándo la intervención paternalista puede estar justificada.» (Y contradiría también la primera premisa de Mill.)

Y cabría también preguntarse si el principio de daño no se basa igualmente en presunciones generales: porque se supone que una acción A daña a terceros es prohibida con carácter de generalidad, aun cuando en un caso particular la suposición sea falsa.

Por último, no hay duda que si no conocemos bien los intereses de cada cual, también se vuelve muy difícil, por no decir imposible, un cálculo del bienestar general, tal como el perseguido por el utilitarismo. Y no es tan claro que la humanidad salga siempre ganando si se permite a cada cual que viva como le plazca. También el principio de daño excluye normativamente la 
posibilidad de realizar todo tipo de vida, con una clara ventaja para la sociedad en general.

$\mathrm{Si}$ se abandona el argumento del utilitarismo, puede buscarse una nueva vía recurriendo al argumento de la libertad también sostenido por Mill, es decir,

2. El argumento del respeto de la autonomía de la persona.

La intervención paternalista del Estado destruye la autonomía individual, se dice, y conduce fatalmente a la servidumbre (F. A. Hayek).

Conviene detenerse un poco y analizar el concepto de autonomía en su relación con el paternalismo. Para ello seguiré la propuesta de Douglas N. Husak (1981). Pueden distinguirse, por lo menos tres versiones de la autonomía:

a) Autonomía como oportunidad del agente para ejercer su capacidad de elección:

«Una persona es autónoma en este sentido en la medida en que se han eliminado todos los impedimentos para que en la oportunidad del caso pueda ejercer su libertad de acción» (1981, 34).

Un ejemplo claro de este tipo de impedimento es cuando se coloca a alguien una camisa de fuerza.

Parece que hay pocos casos de paternalismo jurídico que puedan ser encuadrados dentro de este tipo de restricciones. Los cinturones de seguridad no pueden ser considerados como una camisa de fuerza y las personas que en un accidente resultan dañadas por no haber usado cinturón de seguridad tienen menos oportunidades de llevar a cabo sus decisiones. Ronald Dworkin habla por ello en estos casos de «freedom-maximazing-paternalism».

b) Autonomía como capacidad de elección.

Una persona con una camisa de fuerza tiene capacidad de elección aunque no pueda ejercerla. Algunas técnicas psico-quirúrgicas con personas que tienen un comportamiento desviado pueden ser considerados como casos paradigmáticos de interferencias con la capacidad de elección.

Es difícil decir que las intervenciones paternalistas privan por lo general a las personas de este tipo de autonomía. Puede estarse bajo coacción y, sin embargo, no perder este tipo de autonomía. Y más aún, hasta puede sostenerse con Husak que:

«Si una intervención paternalista es eficaz para proteger el bienestar físico del agente, su capacidad de elección está en realidad preservada por la interferencia» $(1981,37)$. 
Supongamos, sugiere Husak que el uso aditivo de ciertas drogas disminuye la capacidad de elección; en este caso, los filósofos que sostengan el valor de este tipo de autonomía tendrían que estar a favor de medidas razonales para inducir coactivamente a estas personas a que no consuman drogas, a pesar de que aquéllas tendrían carácter paternalista.

Pero habría otra estrategia par argumentar contra el paternalismo desde el punto de vista de esta concepción de la autonomía. Podría decirse que cuando se actúa paternalistamente no se le permite a la persona que elija y que la elección es hecha por otro. En este sentido deja de ser autónoma, es decir, no obedece las leyes que ella misma se impone y se entra en el campo de la heteronomía con lo que se abandona el ámbito de la moral.

Pero si se toma en serio este argumento, esto valdría para todo tipo de interferencias, también para aquéllas que no son paternalistas, es decir, que se basan en el principio del daño a terceros. En este caso, si se quiere ser coherente habría que decir que la prohibición de matar impuesta al asesino potencial lo priva de su libertad de elección (matar o no matar impunemente) y que por tanto violaría su autonomía, es decir, se trataría de una prohibición moralmente injustificable, argumento que no estaría dispuesto a aceptar quien defiende la vigencia exclusiva del principio de daño.

c) Autonomía como conformidad con la ley moral.

Esta tercera versión sostiene que no hay que confundir autonomía con libertinaje y, por tanto, lo que interesa es no sólo la capacidad de elegir sino el contenido de la elección. Podría hablarse de autonomía si este contenido coincide con la moral. Pero la incompatibilidad o compatibilidad del paternalismo con esta versión de la autonomía, como afirma Husak, «no puede ser afirmada independientemente de una investigación del contenido de la moral. Es simplemente una petición de principio asumir sin argumento que la teoría moral correcta tiene que proscribir todo tipo de interferencia paternalista» (1981, 39). Lo que habría que demostrar es que el paternalismo es inmoral para poder luego inferir que se ha producido una violación de la autonomía.

Si se considera que la estrategia de la autonomía no es muy fecunda para combatir el paternalismo, podría recurrirse a una tercera vía:

\section{El argumento de la violación del principio de igualdad.}

Toda medida paternalista, se dice, presupone por definición una relación de supra y subordinación, que viola uno de los principios básicos de una sociedad democrática: el principio de igualdad. 
Si se miran las cosas más de cerca, no es difícil concluir que esta afirmación radical es falsa. Existen por lo pronto los casos de paternalismo recíproco: un matrimonio que no desea engordar pero que tiene una tendencia a comer dulces puede establecer una relación de control mutuo en el que cada uno de los cónyuges impida al otro ceder a la tentación de las confiterías. Estos casos, en los que se procura combatir la debilidad de la propia voluntad, se dan también en el ámbito del paternalismo jurídico cuando el Estado interviene para impedir que con su comportamiento el individuo lesione intereses propios a los que reconoce como más importantes que los deseos que motivan su conducta actual (Nino, 1984, 144). David Hume, (1956, II, 237) ha dado una formulación clásica de las causas psicológicas de la aceptación de este paternalismo:

«Cuando reflexiono sobre una acción que habré de realizar dentro de un año, prefiero siempre el bien mayor, sin importarme si en ese momento estará más o menos próximo; ninguna diferencia al respecto influye en mis actuales intenciones y decisiones. La distancia que me separa de la decisión final hace que se desvanezcan estas pequeñas diferencias de modo que no me veo afectado sino por las casualidades generales y discernibles del bien y del mal. Pero cuando me voy acercando a la fecha, las circunstancias que al principio no había tenido en cuenta comienzan a cobrar importancia e influyen en mi conducta y en mis afectos. Surge ahora una inclinación especial hacia el presente y me resulta ya dificil adherirme inflexiblemente a mi intención y resolución primeras. Esta debilidad natural puedo lamentarla en alto grado y procurar por todos los medios posibles liberarme de ella. Puedo recurrir al estudio y a la reflexión o al consejo de los amigos, a la frecuente meditación y a la reiterada resolución. Y habiendo experimentado cuán ineficaz es todo ello, puedo recurrir con alegría a cualquier otro medio mediante el cual me puedo imponer una restricción a mí mismo y me protejo frente a la flaqueza.»

Los llamados «contratos Ulises» pueden ser incluidos también dentro de este tipo de paternalismos, en los cuales no parece ser muy feliz la expresión de supra y subordinación, si es que con ella se quiere indicar una violación del principio de igualdad. El ciudadano, precisamente porque suele razonar como Ulises o de acuerdo con la explicación psicológica de Hume, puede recurrir al Estado y solicitarle su intervención paternalista para que retire de su sueldo todos los meses los aportes necesarios para la jubilación, justamente para evitar el daño futuro que podría resultar de su debilidad de voluntad. Es realmente extraño sostener que cuando el Estado actúa en estos casos viola el 
principio de la igualdad democrática. Más bien se podría hablar de aquello que Gerald Dworkin $(1983,29)$ llama «políticas de seguro social» y que son el resultado «racional y prudente del conocimiento de nuestras debilidades y propensiones irracionales». En los regímenes democráticos, los electores suelen dar su consentimiento a la adopción de medidas por parte de sus candidatos cuando asuman el gobierno, por ejemplo, para combatir la inflación o la contaminación ambiental, que, al no ser especificadas de antemano pueden en su caso significar una intervención paternalista estatal. Lo que se otorga en estos casos es una especie de «cheque en blanco», que puede ser cobrado también en contra de la voluntad actual de quien lo emitió.

Pero si el consentimiento anterior de la persona en cuestión justifica la intervención paternalista del Estado, podría avanzarse por esta vía y sostener que en todos los casos en los que existió este consentimiento en realidad no puede hablarse ni siquiera de paternalismo ya que este exige por definición la posibilidad de un daño y nadie puede dañarse voluntariamente. En apoyo de esta afirmación podría recurrirse a una fórmula bien conocida por los juristas: «Volenti non fit injuria.» Esta máxima tiene una larga tradición que se remonta no sólo al Derecho Romano, sino a Aristóteles: «...por necesidad, lo justo y lo injusto requieren más de una persona... nadie comete adulterio con su propia mujer, ni allana su propia casa ni roba lo que le pertenece» $(1985,265)$. En este caso, Aristóteles se refiere a una interpretación de la fórmula «Volenti», según la cual «injuria» significa «agravio» en el sentido de la violación de un derecho. Los juristas conocen también la máxima «nadie puede invocar su propia torpeza», que apunta en esta misma dirección. Y ésta fue la interpretación que utilizó Mill para la formulación de su principio de daño (cfr. Feinberg, 1983, 12).

Pero también Aristóteles había señalado una segunda versión de «injuria» cuando decía que «nada sufre contra su voluntad, de suerte que, al menos en esto no es tratado injustamente, sino que, en todo caso, sólo es perjudicado» $(1985,260)$. Es esta segunda versión de «injuria» la que es relevante para el tratamiento del problema del paternalismo jurídico.

Sostener que los argumentos aducidos en contra del paternalismo jurídico no son muy convincentes no significa, desde luego, haber demostrado la posibilidad de su justificación moral. A este punto quiero ahora referirme. 


\section{III}

Si se admite que es posible que alguien se dañe voluntariamente, es decir se acepta la segunda versión de la máxima «Volenti», y al mismo tiempo se desea poner el acento en la importancia del respeto de la autonomía de la persona, podría centrarse la argumentación justificante de algunos tipos de paternalismo en el consentimiento expreso o hipotético de quien es tratado paternalistamente. Esta es la vía seguida por Gerald Dworkin:

«...la noción básica de consentimiento es importante y me parece ser la única vía aceptable para tratar de delimitar el área del paternalismo justificado $(1983,29)$.

Es obvio que, por definición, este consentimiento no puede ser otorgado en el momento en que se aplica la medida paternalista (sea porque la persona se opone directamente a ella (como en el caso de Ulises cuando pide a sus marineros que lo desaten) sea porque no está en condiciones de hacerlo (por estar inconsciente o tener alteradas sus facultades)). Al caso del consentimiento expreso anterior me he referido al mencionar a Hume y los «cheques en blanco» de Dworkin. Y puede por supuesto suceder que una vez pasado un tiempo después de aplicada la medida paternalista quien fue objeto de la misma reconozca que ella fue acertada. Con el otorgamiento de su consentimiento, la medida paternalista quedaría justificada.

La apelación al consentimiento futuro presenta, sin embargo, dos graves inconvenientes señalados por Murphy $(1974,482)$ : por lo pronto, el consentimiento posterior podría de alguna manera ser «fabricado» por el proceso paternalista. Esto es lo que suele suceder en el caso de regímenes políticos no sólo paternalistas, sino también autoritarios. La sospecha de los liberales extremos al estilo Nozick en el sentido de que el paternalismo jurídico es el primer paso hacia la dictadura quedaría así confirmada. Pero, por otra parte, podría también suceder que aun años después de la intervención paternalista, quien fue objeto de ella no esté dispuesto a aceptarla. En este caso habría que decir que la persona en cuestión debe seguir siendo objeto de atención paternalista porque no comprende la bondad de la medida. Es decir, se argumentaría circularmente: la bondad (o justificación) de la medida paternalista depende del consentimiento futuro y cuando éste no se da decimos que no ha comprendido la bondad de la medida.

El recurso al consentimiento parece indicar más bien otro 
aspecto: no se trata tanto de la existencia efectiva del mismo sino más bien de un «consentimiento hipotético» (Dworkin, 1983², 102), de una hipótesis de racionalidad o de normalidad. Podría pensarse que la medida paternalista está justificada si «toda persona racional podría estar de acuerdo con esta medida» (Gerd/Culver, 1979, 201).

Pero si esto es lo que se quiere decir con «consentimiento futuro o hipotético», lo que en verdad se dice es que quien rechaza la medida paternalista lo hace porque en ese momento no está en condiciones de comprender el alcance de la misma. Un concepto al que podría recurrirse para aclarar esta situación es el de «competencia».

En una primera aproximación, puede sostenerse que «competencia» indica la capacidad de una persona para hacer frente racionalmente o con una alta probabilidad de éxito a los desafíos o problemas con los que se enfrenta. Como existen distintos ámbitos de desafíos o problemas, puede también decirse que la competencia de una persona es siempre relativa al contexto de que se trata. Pedro puede ser competente para interpretar un contrato de compra-venta (Pedro es abogado) pero incompetente para resolver un problema de astrofísica. Pero la competencia o incompetencia puede ser relativa también dentro de un mismo ámbito con relación a diferentes personas. Juan, quien también es abogado, por ser más inteligente que Pedro, puede estar en condiciones de solucionar más rápidamente un problema de interpretación de un contrato. Sin embargo, la mayor o menor rapidez en encontrar la solución es irrelevante para la corrección de la misma. Pero podríamos decir que a pesar de que Pedro y Juan son igualmente competentes, Juan es más competente que Pedro. La aparente contradicción de esta frase indica que aquí estamos utilizando dos conceptos de competencia. Siguiendo una sugerencia de Daniel Wikler (1893, 85 y sigs.), llamaré a la competencia que es común a Pedro y a Juan «competencia básica» $\mathrm{o}$ « $\mathrm{C}_{\mathrm{b}}$ », por lo menos para aquellas disposiciones que se refieren a cuestiones de la vida cotidiana (celebración de contratos simples, comprensión de las disposiciones del Código Penal). Y en los casos en los que se requiere una mayor competencia, es decir, una $" \mathrm{C}_{\mathrm{r}}$, el propio sistema así lo establece (por ejemplo, las disposiciones que exigen la presencia de un abogado para actuar en juicio).

La falta de $\left\langle\mathrm{C}_{\mathrm{b}}\right\rangle$ diré que es condición necesaria aunque no suficiente para la justificación de medidas paternalistas. Pienso que es plausible decir que alguien carece de $« \mathrm{C}_{\mathrm{b}} »$ por lo menos en los siguientes casos: 
a) cuando ignora elementos relevantes de la situación en la que tiene que actuar (tal es el caso de quien desconoce los efectos de ciertos medicamentos o drogas o de quien se dispone a cruzar un puente y no sabe que está roto, para usar el ejemplo de Mill);

b) cuando su fuerza de voluntad es tan reducida o está tan afectada que no puede llevar a cabo sus propias decisiones (es el caso de Ulises, el de los alcohólicos y drogadictos que menciona el $\S 114$ del Código Civil alemán, o el de la flaqueza del que hablaba Hume);

c) cuando sus facultades mentales están temporal o permanentemente reducidas (a estos casos se refieren las disposiciones jurídicas que prohíben los duelos, o las relacionadas con la curatela de los débiles mentales);

d) cuando actúa bajo compulsión (por ejemplo, bajo hipnosis o bajo amenazas).

e) cuando alguien que acepta la importancia de un determinado bien y no desea ponerlo en peligro, se niega a utilizar los medios necesarios para salvaguardarlo, pudiendo disponer fácilmente de ellos. La incoherencia que resulta de querer $X$, saber que $Y$ es condición necesaria para lograr $X$, disponer de $Y$, no tener nada que objetar contra $Y$ y no utilizarlo, es un síntoma claro de irracionalidad (Dworkin, 1983 $\left.{ }^{1}, 30\right)$. Ello permite incluir a la persona en cuestión en la categoría de quienes carecen de una competencia básica (es el caso de la obligación de los cinturones de seguridad en los automóviles y de los cascos de los motociclistas).

En todos estos casos, quien presenta una carencia de $\left\langle\mathrm{C}_{\mathrm{b}}\right\rangle$, es decir, es incompetente básico $\left(« \mathrm{I}_{\mathrm{b}} »\right)$ tiene un déficit con respecto a la generalidad de sus congéneres y en este sentido puede decirse que se encuentra en una situación de desigualdad negativa. Que esta « $\mathrm{I}_{\mathrm{b}}$ » puede ser permanente o temporaria, sectorial o total, se infiere de los casos aquí mencionados.

Es obvio que la « $\mathrm{I}_{\mathrm{b}} »$ puede ser atribuida con mayor o menor arbitrariedad y calificar de $« \mathrm{I}_{\mathrm{b}} »$ a un individuo o a todo un pueblo como cuando, por ejemplo, se le atribuye incapacidad para el manejo de las instituciones democráticas. Por ello si lo que nos interesa es referirnos a la « $\mathrm{I}_{\mathrm{b}}$ » como condición necesaria para la justificación del paternalismo, convendrá exigir que esta incapacidad básica tenga un fundamento objetivo. En este sentido, parece acertado recurrir como criterio para la atribución o rechazo de una competencia básica a relaciones causales seguras (tal es el caso, por ejemplo, de los efectos de las drogas o del 
alcohol o de la hipnosis o aquellas situaciones que Dworkin $\left(1983^{1}, 30\right)$ llama «cognitive delusions» (cuando alguien cree que si salta por la ventana habrá de flotar en el aire) o a criterios de incoherencia lógica como en el caso $e$ ).

El limitar los casos de paternalismo justificable a los « $\mathrm{I}_{\mathrm{b}} »$ y no extenderlos a los $\left\langle\mathrm{I}_{\mathrm{r}}\right\rangle$ es importante para evitar caer en una sociedad regida sólo por los más talentosos o informados de sus miembros. El paternalismo justificable no tiene por ello nada que ver con un Estado platónico gobernado por filósofos.

Que la existencia de una « $\mathrm{I}_{b} »$ elimina la objeción contra el paternalismo planteada por los propios liberales es algo que Mill parece también advertirlo cuando hablaba en el pasaje citado al comienzo de «cualquier miembro de una sociedad civilizada». La inclusión del calificativo "civilizada» indica por otra parte, que la $\left\langle\mathrm{C}_{\mathrm{b}}\right.$ » es también en cierto modo relativa. La competencia básica que se exige en una «sociedad civilizada» o «moderna» puede ser muy diferente a la de una «sociedad primitiva». Y es probable que a medida que aumenta la complejidad de una sociedad, aumente también el nivel de la $« \mathrm{C}_{\mathrm{b}}$ » $\mathrm{y}$ consecuentemente el número de «incompetentes básicos» (basta pensar en la incompetencia del ciudadano común para llenar un formulario de impuestos). En esto reside el peligro que muchos ven en una sociedad altamente tecnificada. Pero esto no altera la relevancia de la «䀡》 como condición necesaria para la imposición de medidas paternalistas justificables.

Desde luego, la verificación de que alguien es $\left\langle\mathrm{I}_{b} »\right.$ no basta para justificar la intervención paternalista. Podría muy bien sostenerse como el juez Brandeis de la Suprema Corte de los Estados Unidos que «El derecho que más aprecia toda persona civilizada es el derecho a que la dejan tranquila» o afirmar que cada cual tiene que hacer su vida con las competencias y capacidades que les son propias y que lo más que puedo hacer cuando me encuentro con un « $\mathrm{I}_{\mathrm{b}}$ » es compadecerme verbalmente de su destino y dejar que se las arregle por su cuenta. El paternalismo justificable requiere además un interés benevolente (Murphy $1974,465)$ en el «I $\mathrm{I}_{b} »$ con miras a superar los inconvenientes que trae aparejada la incompetencia básica para el propio incompetente, es decir, procurar que no se dañe a sí mismo. Si este interés benevolente no está presente, entonces o bien se interviene sólo en los casos en los que es aplicable el principio de daño a terceros o se instrumentaliza al « $\mathrm{I}_{\mathrm{b}} »$.

Es obvio que la aplicación de medidas paternalistas supone una relación de superioridad en muchos casos, y, en este sentido de desigualdad. Ello se debe a la definición misma de incompetencia. 
Pero el propósito de la medida paternalista justificable es justamente la superación de la desigualdad. Porque ello es así, puede Rawls afirmar que en la posición originaria, las personas

«desearán asegurarse en contra de la posibilidad de que sus facultades estén subdesarrolladas y no puedan promocionar racionalmente sus intereses, como en el caso de los niños; o que por alguna desgracia o accidente sean incapaces de tomar decisiones para su propio bien como en el caso de quienes están severamente dañados o mentalmente perturbados. Es racional para ellas protegerse en contra de sus inclinaciones irracionales..., aceptando ciertas disposiciones destinadas a evitar las consecuencias desafortunadas de su comportamiento imprudente. Para estos casos, las partes adoptan principios que estipulan cuando otros están autorizados para actuar en su nombre o para dejar de lado sus deseos actuales si es necesario...» $(1971,248$ y sigs.)

Precisamente porque el paternalismo justificable apunta a la superación de una desigualdad resultado de una incompetencia básica, podía decir Rousseau (1964, III, 182) que la autoridad paternal «toma más en cuenta la ventaja del que obedece que la utilidad del que ordena». Fotion (1979) parece haber recogido esta idea con su sugerencia de la «implicación completa» aplicada al modelo paternalista, es decir, que quien actúa paternalistamente (sea que se trate de un individuo, de una institución o del Estado) tiene que hacerlo no sólo por ser más sabio o estar mejor informado sino guiado por el interés de la persona a quien se dirige su tratamiento paternalista $(1979,197)$.

Las dos condiciones mencionadas son necesarias y su conjunción las transforma en suficientes. El razonamiento justificante de una medida paternalista tiene pues que partir de dos premisas, una de tipo empírico (la verificación de una incompetencia básica) y otra de tipo ético normativo (el déficit provocado por una incompetencia básica debe ser superado, justamente en aras de la autonomía y la igualdad que quienes sostienen la vigencia exclusiva del principio de daño consideran que son puestas en peligro por el paternalismo jurídico).

Si se admite esto, habrá que concluir que no está éticamente justificable interferir en los siguientes casos:

a) cuando alguien con competencia básica quiere dañarse y hasta privarse de la vida para castigarse a sí mismo o porque considera que la vida carece ya de sentido y la muerte es una liberación. Es el caso de quienes toman conciencia de su propia culpa y se convierten en jueces de ellos mismos como en los 
ejemplos de Edipo, Judas o Rascolnicov. La segunda alternativa es el caso de Werther o de Séneca cuando decía: «En contra de todas las ofensas de la vida tengo siempre el refugio de la muerte.»

b) cuando alguien que posee competencia básica prefiere correr el riesgo de un daño seguro o altamente probable en aras de su propio placer o felicidad:

«Sin cuidado me tiene el más allá. De esta tierra es de donde manan mis goces y este sol el que alumbra mis dolores: luego que yo los deje a ambos, que pase lo que pasar quiera y pueda... Si logras lisonjearme, trapacero, con la idea de que podré yo alguna vez estar contento de mí mismo, si con el deleite puedes engañarme, sea ese para mí el último día de mi vida... Luego podrás cargarme de cadenas y yo me iré gustoso a pique.»

«Todos estamos cerca de la muerte. Lo único que sucede es que nosotros estamos un poco más cerca de ella porque sobre nosotros pende la espada de Damocles. A veces hay que correr riesgos en la vida; en caso contrario ella no valdría nada. Piense en el caso de los alpinistas. Me parece estupendo lo que hacen. Y, por otra parte, ¿qué significa riesgo? Todas las vías conducen a la muerte.»

La primera frase la dice el doctor Fausto en la escena III del primer acto de la obra de Goethe; la segunda, Alain Prost, campeón de Fórmula 1 en una entrevista con el semanario Der Espiegel del 25 de agosto de 1986.

c) cuando alguien con competencia básica arriesga su vida en aras de los demás. En esta categoría pueden ser incluidos quienes sustentan el ideal del héroe.

En los casos de un $\left\langle\mathrm{C}_{\mathrm{b}}\right\rangle$ que desea poner fin a su vida o correr riesgos extraordinarios, el paternalismo jurídico no es justificable de acuerdo con la fórmula aquí propuesta. Lo único que aquí cabe es, si se considera oportuno, utilizar el consejo o el llamado a la reflexión. Sólo si se acepta una concepción metafísico-religiosa del valor de la vida, como la que sostenía, por ejemplo Locke, o William Blackstone cuando afirmaba que «el mero acto del suicidio es prueba evidente de locura» (con lo que por supuesto se coloca al suicida en la categoría de los « $\mathrm{I}_{\mathrm{b}} »$ ) (cfr. Blom-Cooper y Drewry 1976, 203) es posible justificar la prohibición del suicidio o de las actividades que ponen en grave peligro la vida.

El concepto de incompetencia básica fija un límite que algunos podrán considerar demasiado bajo. Sin embargo, me parece que es aconsejable mantenerse en esta línea de mínima y que los 
casos situados por encima de ella se encuentran en una zona de penumbra en la cual es muy difícil proponer criterios de aplicación universal. Basta pensar en el caso de una posible prohibición general de fumar. El fumador podría ser asimilado al caso e) de las incompetencias básicas pero también al caso b) de quienes prefieren correr un riesgo más o menos seguro de reducir sus posibilidades de vida en aras del placer de fumar. Personalmente me inclino por esta segunda posibilidad. El argumento del peso de la tradición sugerido por Glover $(1977,180)$ o el de Donald H. Regan $(1983,120)$ en el sentido de que el montañismo «es una actividad intrínsecamente más valiosa que fumar» me parecen aventurados y me hacen pensar que tanto Glover como Regan no son fumadores. Otra es la cuestión de saber si el Estado puede desalentar ciertas actividades consideradas como riesgosas (tal es el caso de la prohibición de la propaganda de cigarrillos o la negativa de las compañías de seguros a celebrar contratos de seguros de vida con montañistas o con corredores de Fórmula 1).

Y por supuesto que tampoco es justificable intervenir en el comportamiento de los « $\mathrm{I}_{b}$ » cuando ello no se hace con intención de superar el déficit de una incompetencia básico sino justamente para reforzar una desigualdad. Nada más fácil y más reprochable moralmente que la instrumentalización de los « $\mathrm{I}_{\mathrm{b}} »$.

La aceptación de estas dos condiciones necesarias y conjuntamente suficientes para la justificación moral del paternalismo jurídico permiten interpretarlo no sólo como moralmente permitido sino que también es posible afirmar que está moralmente ordenado como un medio eficaz para la reducción de las desigualdades. Es en este sentido un complemento necesario del principio de daño a terceros susceptible de ser interpretado como una obligación moral positiva.

Es claro que las disposiciones jurídicas se refieren a grupos de personas y tienen en este sentido un carácter general. La inclusión de una determinada persona en una clase de « $\mathrm{I}_{b}$ » es un problema con el que los juristas están bien familiarizados. Pero de aquí no puede inferirse que sobre la base del principio del paternalismo jurídico no es posible prohibir u ordenar «tipos generales de conducta» como sostiene John D. Hodson $(1983,49)$.

En esta exposición he recurrido continuamente al concepto de daño. Alguien podría sugerir que este concepto no ha sido aquí definido y que por tanto lo aquí dicho es insuficiente para tratar el problema del paternalismo. A esta posible objeción 
quiero referirme con unas breves consideraciones finales. El concepto de «daño» es un concepto con carga moral que presupone la determinación previa de lo que debe ser considerado como valioso y digno de protección. Todo sistema jurídico es en este sentido expresión de la moral positiva o «mores» de quienes adoptan frente a él lo que Hart ha llamado «punto de vista interno». En este nivel conviene situar el problema de la legitimación de un sistema jurídico-político. Si se admite que el concepto de daño es un concepto moral que es recogido por el orden jurídico vigente, la tesis del «moral disestablishment» es falsa.

Es claro que la lista de bienes dignos de ser protegidos varía según las sociedades y los tiempos históricos. Con la lista de los bienes varía también la lista de los daños. En este sentido se puede hablar de medidas paternalistas permitidas u ordenadas en el sistema jurídico $S$ y prohibidas en $S^{l}$. Pero en ambos casos, dentro del marco de cada sistema jurídico, el concepto de daño que se utiliza cuando se habla de daños a terceros y de daños que la propia persona puede causarse es el mismo. No es que el daño a terceros sea más importante que el que uno puede causarse a sí mismo.

Si se admite, como creo que es correcto, que el punto de vista interno es condición necesaria aunque no suficiente de la existencia de un ordenamiento jurídico positivo y que aquél es expresión de la mores de los grupos políticamente significativos, no hay duda que el ordenamiento jurídico cumple, en este sentido, una función moralizante y si no refleja necesariamente el consenso moral de la población, al menos trata de generarlo (MacCormick, 1982, 34). Admitir esto significa adoptar una posición menos radical que la de Lord Devlin cuando decía que una sociedad no es un pueblo sino una comunidad de ideas, sin caer necesariamente en la identificación de crimen y pecado como temían los autores del Wolfenden Report. Sólo si se acepta la tesis extrema de la coparticipación unánime de una moral positiva puede concluirse que su violación, aun en la esfera privada, es una especie de traición a la sociedad, como afirmaba Devlin. Pero también es verdad, cosa que no está tan clara en las críticas de Hart a Devlin (1963), que una alteración de la moral positiva de los grupos dominantes implica un cambio en el punto de vista interno y en este sentido puede significar una alteración del sistema político-jurídico.

Muy distinta es la relación que existe entre un sistema jurídico positivo y la moral crítica o ética. Cuando un sistema jurídico positivo responde a las exigencias de la moral crítica puede decirse que posee legitimidad. A diferencia de la legitimación, la 
legitimidad no es condición necesaria para la existencia de un sistema jurídico positivo, como parecen sostenerlo los partidarios de una versión extrema del moralismo jurídico.

Los argumentos que he procurado presentar apuntan a una justificación ética de algunas formas de paternalismo jurídico. Por ello la referencia al respeto de la autonomía de la persona y al principio de igualdad. Sólo cuando la medida en cuestión, aplicada a un « $\mathrm{I}_{\mathrm{b}}$ », promueve o defiende su autonomía o aspira a la superación de un déficit de igualdad puede hablarse paternalismo éticamente justificado. Es obvio en este sentido que formas de paternalismo jurídico practicados en el pasado o en la actualidad no son éticamente justificables por más que puedan ser justificables desde el punto de vista de la moral positiva de los grupos dominantes. Estos casos ilustran una vez más la diferencia entre legitimación y legitimidad de un sistema jurídico-político, que no he de entrar a analizar aquí (para una exposición de este problema cfr. Garzón Valdés 1986).

Por supuesto que alguien podría poner en duda la posibilidad de una fundamentación racional de la ética o recoger la sugerencia de Borges en el sentido de que la ética es «una ilusión de los hombres» y concluir que existen tantos paternalismos éticamente justificables como morales positivas. Pienso que esto es falso pero la demostración de su falsedad superaría los límites que aquí me había impuesto. 


\section{BIBLIOGRAFÍA}

Aristóteles (1985), Ética Nicomáquea, Madrid.

Blom-Cooper, Louis y Gavin Drewry (1976), Law and Morality, Londres.

Brock, Dan (1983). «Paternalism and Promoting the Good», en Rolf Sartorius, Paternalism, University of Minnesota Press.

Fotion, N. (1979), «Paternalism», en Ethics, vol. 89, núm. 2, 191-198.

Dworkin, Gerald $\left(1983^{1}\right)$, «Paternalism», en Rolf Sartorius (comp.), Paternalism, University of Minnesota Press.

—, $\left(1983^{2}\right)$, «Paternalism: Some Second Thoghts», en Rolf Sartorius (comp.), Paternalism, University of Minnesota Press.

Feinberg, Joel (1983), «Legal Paternalism», en Rolf Sartorius, (comp.), Paternalism, University of Minnesota Press.

Garzón Valdés, Ernesto (1986), Überlegungen zum Begriff der Stabilität politischer Systeme, Maguncia.

Gerd, Bernard y Charles M. Culver (1979), «The Justification of Paternalism», en Ethics, vol. 89, núm. 2, 199-210.

Glover, Jonathan (1977), Causing Death and Saving Lives, Harmondsworth.

Hart H. L. A. (1963), Law, Liberty and Morality, Standford University Press.

Hobson, eter (1984), «Another Look at Paternalism», en Journal of Applied Philosophy, vol. 1, núm. 2, 293-305.

Hodson, John D. (1983), The Ethics of Legal Coercion, Dordrecht.

Hume, David (1956), A Treatise of Human Nature, 2 vols., Londres.

Husak, Douglas N. (1981), «Paternalism and Autonomy», en Philosophy and Public Affairs, 1981, vol. 10, núm. 1, 27-46.

Lyons, David (1984), Ethics and the rule of law, Cambridge.

MacCormick, Neil (1982), «Against moral disestablishment», en del mismo autor Legal Right and Social Democracy, Oxford.

Mill, John Stuart (1978), On Liberty, Glasgow.

Murphy, Jeffrie G. (1974), «Incompetence and Paternalism» en ARSP, LX, núm. 4, 465-486.

Nino, Carlos S. (1984), Ética y derechos humanos, Buenos Aires.

Rawls. John (1971), A Theory of Justice, Oxford.

Regan, Donald H. (1983), «Paternalism, Freedom, Identity, and Commitment», en Rolf Sartorius (comp.), Paternalism, University of Minnesota Press.

Rousseau, J. J. (1964), Oeuvres complètes, 4 vols., París.

Tur, Richard (1985), «Paternalism and the Criminal Law», en Journal of Applied Philosophy, vol. 2, núm. 2, 173-190).

Daniel Wikler (1983), «Paternalism and the Mildly Retarded», en Rolf Sartorius, Paternalism, University of Minnesota Press. 